\title{
Effect of dental intervention on improvements in metabolic syndrome patients: a randomized controlled clinical trial
}

\author{
Midori Doke ${ }^{1}$, Yuriko Komagamine ${ }^{1 *}$, Manabu Kanazawa ${ }^{1}$, Maiko Iwaki ${ }^{2}$, Hiroyuki Suzuki ${ }^{1}$, Yasunari Miyazaki ${ }^{3}$, \\ Tetsuya Mizuno ${ }^{4}$, Kaori Okayasu ${ }^{5}$ and Shunsuke Minakuchi ${ }^{1}$
}

\begin{abstract}
Background: Metabolic syndrome (MetS), caused by the accumulation of visceral fat, is considered a major cause of cardiovascular disease. This randomized controlled trial aimed to clarify the effect of dental intervention, including prosthodontics and/or periodontal treatment, combined with dietary and exercise guidance on MetS.

Methods: In total, 112 patients who met the Japanese waist circumference criteria of MetS were recruited. The intervention group (ITG) received dental intervention along with dietary and exercise guidance, while the control group (CTG) received dietary and exercise guidance alone. Three outcome measurements were obtained before intervention (BL), 1 month after intervention (1M), and 3 months after intervention (3M).

Results: Body water rate $(p=0.043)$ was significantly higher in ITG than in CTG at 1M. Simultaneously, fasting blood sugar level $(p=0.098)$ tended to be lower in ITG than in CTG. Lean mass $(p=0.037)$ and muscle mass $(p=0.035)$ were significantly higher and body weight $(p=0.044)$ significantly lower in ITG than in CTG at 3M. Body mass index $(p=0.052)$ tended to be lower in ITG than in CTG.
\end{abstract}

Conclusions: Dental intervention combined with lifestyle guidance may improve anthropometric status and reduce the risk of MetS.

Trial registration: University Hospital Medical Information Network Center Unique UMIN000022753. https://uploa d.umin.ac.jp/cgi-open-bin/ctr/ctr_view.cgi?recptno=R000026176.

Keywords: Metabolic syndrome, Obesity, Dental intervention, Periodontal treatment, Prosthodontic treatment

\section{Background}

According to the World Health Report of the World Health Organization [1] (WHO), metabolic syndrome (MetS) has been identified as the main cause of cardiovascular disease, which has been increasing worldwide. The prevalence of MetS among Japanese nationals aged

\footnotetext{
*Correspondence: y.komagamine.gerd@tmd.ac.jp

${ }^{1}$ Gerodontology and Oral Rehabilitation, Graduate School of Medical and Dental Sciences, Tokyo Medical and Dental University, Yushima, Bunkyo-ku, Tokyo, Japan

Full list of author information is available at the end of the article
}

$40-74$ years has been estimated at $19,400,000(15.3 \%)$ by the Japan Ministry of Health, Labor and Welfare [2].

MetS has obesity, diabetes, hypertension, dyslipidemia, and insulin resistance (IR) at its base, and is caused by the accumulation of visceral fat [3]. This IR is characterized by an impaired insulin function, and lack of exercise and abdominal visceral fat have been indicated in IR. Japanese criteria of MetS [4] have been based on the National Cholesterol Education Program-the third revision of the Adult Treatment Panel (NCEP ATP III) [5]. MetS was defined as a status with abdominal obesity (men: $\geq 85 \mathrm{~cm}$, women: $\geq 90 \mathrm{~cm}$ circumference at the navel), in addition 
to more than two of the following three statuses: diabetes (fasting blood sugar level: FBS level $\geq 110 \mathrm{mg} / \mathrm{dl}$ ), hypertension (blood pressure $\geq 130 / 85 \mathrm{mmHg}$ ), dyslipidemia (triglyceride level: TG level $\geq 150 \mathrm{mg} / \mathrm{dl}$ and/or high density lipo-protein level: $\mathrm{HDL}$ level $\leq 40 \mathrm{mg} / \mathrm{dl}$ ).

NCEP ATP III stated two treatment goals in MetS [5]. The first goal was to improve on the major causes of MetS, such as obesity and lack of exercise, and the second goal was the improvement of MetS-related factors, which include diabetes, hypertension, and dyslipidemia. To reduce the risk of MetS, weight reduction and increased physical exercise, maintained concurrently with diet therapy, would be necessary. Thromboprophylaxis medication, combined with general treatment for diabetes, hypertension, and dyslipidemia, should be administered to treat MetS-related factors.

The relationship between MetS and oral environment has been reported. Obese people tend to have a higher prevalence rate of periodontitis than do people with normal stature [6]. Al-Zahrani reported the significant relation between body fat and periodontal disease [7]. The mechanism of pathological correlation between MetS and periodontitis has been explained by Lamster and Pagan, who had reported that inflammatory cytokines mediate host response to periodontal pathogens by activating leucocytes [8]. These cytokines are mediated by adipocytokines secreted from abdominal visceral fat. Therefore, abdominal obesity has been considered to have a strong relationship with periodontitis [9]. This cascade would also increase IR, which would induce systemic imbalance in glucose and lipid metabolism, leading to hyperglycemia and dyslipidemia [10]. In a state of diabetic dyslipidemia, insulin resistance is strongly correlated with elevated TG levels, which would increase serum HDL and LDL, and cause abnormalities in glucose metabolism [11]. Hyperglycemia would cause hyperinflammatory response to periodontium, and impairs resolution of inflammation and repairmen of tissue [12]. From these reports, serum TG, HDL, LDL, glucose and HbA1c have been related to status of both MetS and Periodontitis. As a behavioral fact, Kobayashi suggested in their longitudinal study that the frequency of tooth brushing was related to lower prevalence of MetS [13]. However, those studies indicate correlation between MetS and periodontitis, but the causal relation remains unclear. Considering these reports, obese people tend to be neglectful of oral health behaviors, and this seems to be one of the factors in development of periodontitis, but the impact of oral hygiene on MetS still remains unclear.

Some clinical trials performed periodontal treatment on participants with diabetes [14, 15], obesity [16], and MetS [17], which revealed that inflammatory markers and glycated hemoglobin (HbA1c) levels were reduced after the periodontal therapy. Saengtipbovorn and Taneepanichskul conducted a clinical trial that combined lifestyle guidance and dental care in participants with diabetes [18]. Apart from other previous reports in which they performed periodontal treatment only as intervention, this trial has its novelty in combining lifestyle therapy with periodontal treatment. However, no clinical trial has investigated the combined effect of lifestyle guidance and dental intervention on MetS. By combining dental intervention with lifestyle therapy, additional improvement on MetS would be expected.

Therefore, this randomized controlled trial (RCT) aimed to clarify the effect of dental intervention, including prosthodontics and/or periodontal treatment, combined with dietary and exercise guidance on MetS. The null hypothesis is that no difference exists between the waist circumference and anthropometric measurements of the intervention group (ITG) that received dental intervention along with dietary and exercise guidance and the control group (CTG) that received dietary and exercise guidance alone.

\section{Materials and methods}

This study followed the 2010 Consolidated Standards for Reporting Trials (CONSORT) statement. The trial protocol was approved by the Ethics Committee of the Faculty of Dentistry, Tokyo Medical and Dental University (TMDU; Registration No. D2016-028, date of final registration 25/1/2019), and is registered in the University Hospital Medical Information Network Center (UMIN-CTR Clinical Trial, Unique Trial No. UMIN000022753). All participants provided written informed consent before participation in the study. We recruited 112 patients who met the Japanese waist circumference criteria of MetS. This study was conducted in TMDU Dental Hospital. Participants consisted of TMDU staff and patients who visited TMDU Medical Hospital and/or Dental Hospital. Inclusion criteria were as follows: age $\geq 40$ years, at the time when the consent form was signed; waist circumference criteria for MetS of $\geq 85 \mathrm{~cm}$ for men and $\geq 90 \mathrm{~cm}$ for women at the navel; missing tooth according to Eichner's criteria A2, A3, B1, B2, B3, B4, C1, C2, C3, and/or patients with light-moderate periodontitis $(4 \mathrm{~mm} \leq \mathrm{PD}<6 \mathrm{~mm})$; and signing of consent form after the explanation and understanding of the study objectives. In this study, we have modified the criteria of CPI, and defined $\mathrm{PD} \geq 4 \mathrm{~mm}$ as mild to moderate periodontitis, where the patients would need professional dental care [19]. We excluded PD $>6 \mathrm{~mm}$, which is a status that needs periodontal surgery, since the long healing period after surgery might exceed the ethical time limit of study period. In the Eichner's classification, patients would be divided into three main groups as 
Eichner's index (A, B, and C), according to the occlusal status supported by remaining teeth [20]. Occlusion is supported by four occlusal areas in the healthy dentition composed of the right and left premolars and molars, and areas that support occlusion are called occlusal support areas. Eichner classification groups A, B, and $\mathrm{C}$ were as follows: (A) Occlusal contacts are present in all four posterior support zones; (B) occlusal contacts are present in 1-3 zone(s); (C) occlusal contact is in the anterior region only and / or no occlusal contacts.

Patients were excluded from the study as per the following criteria: involvement in regular dietary and/or exercise guidance outside this study, barriers to attend and/or achieve dietary and exercise guidance and the study objectives, changes in medication prescription within the past 3 months, severe cardiovascular disease, and hyper/hypo function of the thyroid. Further, patients with severe disorders of the liver and/or kidneys, undergoing treatment for cancer, with pregnancy, or with possibility of pregnancy, and others who were judged as ineligible for this study by the principal investigator were excluded from the study. Participants were recruited using the following methods: all the TMDU employees who participated in regular medical examinations received recruiting brochures for this study, with a clear statement that their participation is optional and not compulsory or included as part of their business; posters and flyers were advertised in TMDU Medical and Dental Hospital; and participant selection was entrusted and contracted to competent companies.

A double-blinded parallel group RCT was initiated inside a single facility (TMDU Dental Hospital). Participants were allocated to ITG and CTG. All the patients who had gone through a baseline examination received dietary and exercise guidance, which consisted of the Total Fitness Analysis System (TFAS) [21] and a videoprogrammed dietary and exercise lecture. TFAS is a web application available on the Internet of TMDU, which was created as a life management tool by the TMDU Department of Health Science and Physical Education. This application has its concept based on "Health Promotion 2006: Physical Activity, Exercise, and Physical Fitness" [22], "Exercise Guide 2006" [23], and "Japanese Food Guide Spinning Top" [24]. Participants typed in their recent dietary and exercise records, and they received their results and feedback from TFAS. Thereafter, they were instructed to watch $60 \mathrm{~min}$ of the video lecture about diet and exercise. This program was directed by a specialist in health science. There was no enforcement of specific diet or exercise since this guidance was intended to enhance motivation to improve health. The initial session of Specific Health Guidance [25] took a maximum of $80 \mathrm{~min}$; therefore, the intensity of our trial seemed to be equivalent.

ITG underwent non-surgical periodontal treatment and/or prosthodontics, while CTG would receive their dental intervention after the study period. Three months was considered as the ethical limit to keep the controls away from undergoing needed dental treatment. Nonsurgical periodontal treatment included tooth-brushing instruction (TBI) and supra/subgingival scaling and root planing (SRP). Prosthodontic treatment was performed for patients with missing tooth/teeth according to Eichner's classification: A2, A3, B1, B2, B3, B4, C1, C2, and C3. Fixed partial dentures and removable partial dentures were used to fix the defects. For patients who needed both interventions, periodontal treatment was performed first, and then the prosthodontics was performed next. Six dentists with $>6$ years of clinical experience had performed the dental intervention as operators. As a coordinator, a dentist who was not involved in dental intervention for participants, performed randomization and dietary and exercise guidance, outcome assessment, and statistical analysis.

\section{Outcomes}

The three following outcome measurements were obtained: first, before intervention (BL); second, 1 month after intervention (1M); and third, 3 months after intervention $(3 \mathrm{M})$. To avoid missing data, the investigator rechecked the questionnaires after participants had filled them. The primary outcome of this study was focused on waist circumference, which is the simplest method to assess visceral fat accumulation with accuracy [26]. Waist circumference was measured horizontally around the navel in an upright standing posture. Along with the primary outcome, secondary outcomes, such as blood pressure, blood sample test, and anthropometric measurements using body composition analyzer, were assessed.

Blood pressure was measured to determine the presence of hypertension. The patient's arm was stretched and positioned at the level of the heart in an upright sitting position. Thereafter, the cuff band was wrapped around their arm at the brachial artery. Subsequently, the blood pressure was measured using an electronic sphygmomanometer (OMRON digital automatic sphygmomanometer HEM-1000) [27]. Blood samples were taken to determine hyperglycemia and dyslipidemia through the following indices: TG, HDL, low-density lipoprotein (LDL), FBS, and HbA1c levels. Further, $10 \mathrm{ml}$ blood samples, taken from each patient at the cubital fossa, were then centrifuged and analyzed. Patients were asked to fast for at least $6 \mathrm{~h}$ before the tests. 
TANITA MC-780A [28], a multi-frequency body composition analyzer, was used for the anthropometric measurements. Weight, BMI, body fat percentage, body fat mass, lean body mass, body muscle mass, estimated bone mass, body water mass, and body water percentage were scanned and assessed.

The number of teeth present was counted. Thereafter, the following dental measurements were performed to assess the periodontal statuses of patients: pocket depth $(\mathrm{PD})$ and bleeding on probing (BOP), measured at six sites per tooth.

The sample size estimation was calculated from the change in waist circumference based on an RCT conducted by Munakata [29]. A difference in waist circumference $>3.0 \mathrm{~cm}$ (standard deviation: $5.0 \mathrm{~cm}$ ) within the two groups was regarded as statistically significant. Following the normal distribution of waist circumference, 80 participants were needed to obtain a significance level of 0.05 along with $95 \%$ confidence interval. Considering the dropout rate of $20 \%, 100$ participants (50 in each group) were determined to be the goal of recruitment. For the randomization, sealed opaque envelope system was used to randomly allocate participants into ITG and CTG. For each patient, the coordinator had picked up sealed opaque envelope, and then the treatment allocation was generated. The allocation was written on a paper, which was folded with silver paper, and then was sealed into an opaque envelope. Coordinator had opened the envelope after writing the patient's name onto the envelope. Also, the coordinator had done the preparation of envelopes and enrollment of participants and the assignment of participants. This trial was carried out as double-blinded parallel group RCT, since both the participants and the operator had been unaware of the allocation. Participants were blinded from the group allocation because they were not informed about the groups to which they belonged nor their study schedule. Operators were blinded because the coordinator scheduled the treatment, and they were unaware of the allocation. However, the blinding of the coordinator who performed both the allocation and assessment had been impossible.

\section{Statistical methods}

Student-T test was applied for assessment between groups at baseline, and comparison between dropouts and those who retained. One-way analysis of covariance (ANCOVA) was applied to analyze the difference between the two groups in each assessment of the primary and the secondary outcomes. The difference between each assessment within groups was analyzed using repeated analysis of variance (Repeated ANOVA). Subgroup analysis for patients with missing teeth and those with periodontitis alone was performed to assess the deviation from treatment types using ANCOVA. Analyses were performed using SPSS Version17 software (IBM Japan) [30]. Significance level of 0.05 has been used in each analysis.

\section{Results}

A total of 112 patients visited TMDU Dental Hospital to participate in this study. In the beginning, 100 participants were intended for this study; however, when the target number was recruited, there were 25 dropouts. Because the dropout rate was expected to be $<20 \%$, additional recruitment was done. As shown in Fig. 1, 82 patients completed up to $3 \mathrm{M}$, and 30 dropped out. Among those that completed the trial, 39 were assigned to ITG (men 26, women 13) and 43 to CTG (men 22, women 21). (Fig. 1) There was no significant difference in age, sex, waist circumference, weight, and BMI at base line between groups. All participants needed periodontal treatment. At the same time, one participant from ITG and two from CTG needed fixed partial dentures, and 12 participants from ITG and 14 from CTG needed removable partial dentures to replace the missing teeth (Table 1).

Results of comparisons between groups are shown in Table 2 . Body water rate $(p=0.043)$ was significantly higher, while $\mathrm{PD} \geq 4 \mathrm{~mm}(p=0.000)$ and $\mathrm{BOP}(p=0.001)$ were significantly lower in ITG than in CTG at $1 \mathrm{M}$. Simultaneously, FBS level tended to be lower in ITG than in CTG. Lean mass $(p=0.037)$ and muscle mass $(p=0.035)$ were significantly higher, and body weight $(p=0.044), \mathrm{PD} \geq 4 \mathrm{~mm}(p=0.000)$, and BOP $(p=0.002)$ were significantly lower in ITG than in CTG at 3M. Further, BMI tended to be lower in ITG than in CTG. Comparisons within groups, shown in Table 3, revealed anthropometric improvements in both groups at BL-1M and BL-3M. At BL-1M, ITG had marked significant increase in body water rate $(p=0.000)$ and significant decrease in body fat rate $(p=0.007)$, fat mass $(p=0.005)$, waist circumference $(p=0.004)$, systolic $(p=0.000)$ and diastolic $(p=0.004)$ blood pressures, $\mathrm{PD} \geq 4 \mathrm{~mm}$ $(p=0.000)$ and BOP $(p=0.000)$. Along with that, body weight had tendency of decrement in ITG. Within CTG, significant reductions in waist circumference $(p=0.003)$, and systolic $(p=0.000)$ and diastolic $(p=0.016)$ blood pressures were observed. Moreover, at BL-3M, ITG had marked significant decrease in body weight $(p=0.014)$, BMI $(p=0.016)$, waist circumference $(p=0.000)$, systolic blood pressure $(p=0.001), \mathrm{PD} \geq 4 \mathrm{~mm}(p=0.000)$, and BOP $(p=0.000)$. At the same time, tendency of decrease in fat mass and diastolic blood pressure was observed in ITG. Within CTG, significant reduction in waist circumference $(p=0.001)$, and systolic $(p=0.000)$ and diastolic 


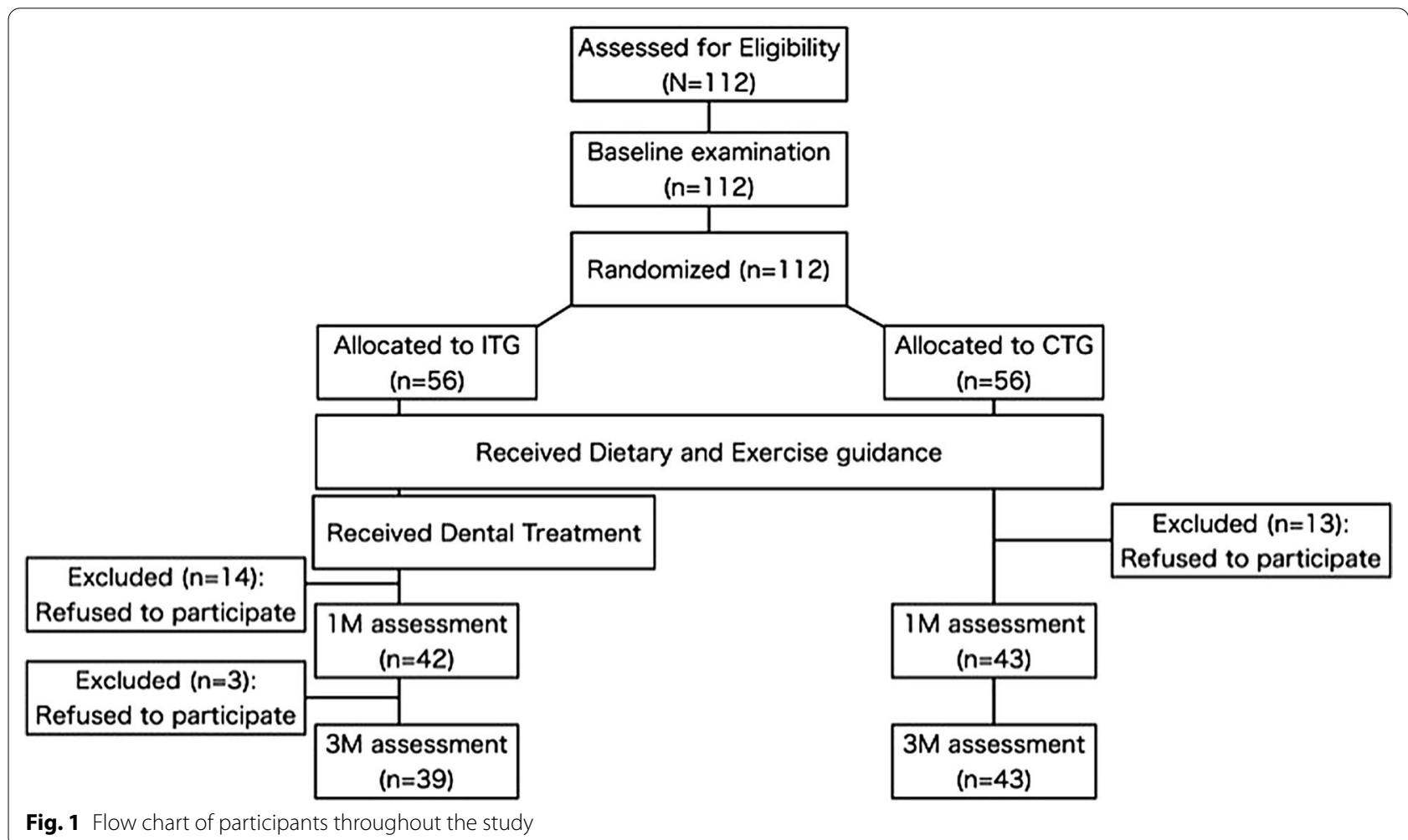

Table 1 Baseline characteristics of the participants

\begin{tabular}{|c|c|c|c|c|}
\hline & \multicolumn{2}{|l|}{ Group } & \multicolumn{2}{|l|}{ Total $(n=82)$} \\
\hline & Control $(n=43)$ & Intervention $(n=39)$ & & $p$ value \\
\hline Age (years), mean (SD) & $56.7(10.3)$ & $58.4(9.4)$ & $57.5(9.9)$ & $0.454^{\mathrm{a}}$ \\
\hline Gender, n (\%) & & & & $0.183^{b}$ \\
\hline Male & $22(51.2 \%)$ & $26(66.7 \%)$ & $48(58.5 \%)$ & \\
\hline Female & $21(48.8 \%)$ & $13(33.3 \%)$ & $34(41.5 \%)$ & \\
\hline Body height (cm), mean (SD) & $163.8(8.2)$ & $166.7(8.5)$ & $165.2(8.4)$ & $0.119^{\mathrm{a}}$ \\
\hline Body weight (kg), mean (SD) & $74.0(14.2)$ & $74.3(9.6)$ & $74.1(12.1)$ & $0.890^{\mathrm{a}}$ \\
\hline BMI, mean (SD) & $27.5(4.2)$ & $26.8(3.3)$ & $27.1(3.8)$ & $0.407^{\mathrm{a}}$ \\
\hline Waist circumference (cm), mean (SD) & $98.4(9.2)$ & $97.8(6)$ & $98.1(7.8)$ & $0.727^{\mathrm{a}}$ \\
\hline \multicolumn{5}{|l|}{ Types of treatment in need, $\mathrm{n}(\%)$} \\
\hline Periodontal treatment & $43(100 \%)$ & $39(100 \%)$ & $82(100 \%)$ & \\
\hline Fabrication of fixed partial denture & $2(4.7 \%)$ & $1(2.6 \%)$ & $3(3.7 \%)$ & \\
\hline Fabrication of removable partial denture & $14(9.3 \%)$ & $12(30.8 \%)$ & $26(31.7 \%)$ & \\
\hline $\mathrm{PD} \geq 4 \mathrm{~mm}$ (\% of sites), mean (SD) & $15.1(14.9)$ & $19.1(16.3)$ & $17.0(15.6)$ & $0.243^{\mathrm{a}}$ \\
\hline BOP (\% of sites), mean (SD) & $20.0(18.4)$ & $25.3(21.4)$ & $22.6(19.9)$ & $0.235^{\mathrm{a}}$ \\
\hline Missing tooth (n), mean (SD) & $3.6(4.9)$ & $3.2(2.9)$ & $3.4(4.1)$ & $0.658^{\mathrm{a}}$ \\
\hline
\end{tabular}

Data are presented as mean (standard deviation) (for all such values)

a Statistical analysis using student's $t$ test

b Statistical analysis using chi-square test

blood pressures $(p=0.020)$ were marked. Furthermore, tendency of decrease in body fat rate, and tendency of increment in lean mass and muscle mass were observed in CTG. At $1 \mathrm{M}-3 \mathrm{M}$, significant reductions in body water rate $(p=0.009)$ and tendency of increment in TG were marked in ITG. 
Table 2 Comparisons of anthropometric measurements, dental measurements, blood pressure, and blood samples between the control group $(n=43)$ and the intervention group $(n=39)$ before and after treatment

\begin{tabular}{|c|c|c|c|c|c|c|c|c|}
\hline & \multirow{2}{*}{\multicolumn{2}{|c|}{$\begin{array}{l}\text { Baseline } \\
\text { Mean }\end{array}$}} & \multicolumn{3}{|l|}{$1 M$} & \multicolumn{3}{|l|}{$3 M$} \\
\hline & & & \multicolumn{2}{|l|}{ Mean } & \multirow[t]{2}{*}{$p$ value* } & \multicolumn{2}{|l|}{ Mean } & \multirow[t]{2}{*}{$p$ value* } \\
\hline & Control & Intervention & Control & Intervention & & Control & Intervention & \\
\hline Weight (kg) & $74.0(14.2)$ & $74.3(9.6)$ & $73.8(14.9)$ & $73.5(9.1)$ & 0.17 & $73.9(15.2)$ & $73(9.2)$ & $0.044^{*}$ \\
\hline Body fat rate (\%) & $32.2(10.3)$ & $29.7(8.1)$ & $31.7(9.8)$ & $28.7(8)$ & 0.16 & $31.3(10.4)$ & $28.9(7.9)$ & 0.89 \\
\hline Body fat mass (kg) & $24.3(10.5)$ & $22.1(7)$ & $23.9(10.5)$ & $21.1(6.7)$ & 0.12 & $23.7(11)$ & $21.3(6.6)$ & 0.45 \\
\hline Lean mass (kg) & $49.7(10.1)$ & $52.2(8.9)$ & $49.9(9.8)$ & $52.4(8.8)$ & 0.76 & $50.3(10.1)$ & $51.9(8.7)$ & $0.037^{*}$ \\
\hline Muscle mass (kg) & $47(9.6)$ & $49.4(8.6)$ & $47.1(9.4)$ & $49.6(8.4)$ & 0.76 & $47.5(9.7)$ & $49.1(8.4)$ & $0.035^{*}$ \\
\hline Estimated bone mass $(\mathrm{kg})$ & $2.7(0.5)$ & $2.8(0.4)$ & $2.8(0.4)$ & $2.8(0.4)$ & 0.8 & $2.8(0.4)$ & $2.8(0.4)$ & 0.11 \\
\hline Body water mass (kg) & $35.8(6.4)$ & $36.1(5.4)$ & $35.8(5.9)$ & $36.7(5.6)$ & 0.18 & $36(5.8)$ & $36(5.5)$ & 0.24 \\
\hline Body water rate (\%) & $48.7(5.8)$ & $48.7(4.2)$ & $49(5.3)$ & $49.9(4.3)$ & $0.043^{*}$ & $49.3(5.9)$ & $49.4(4.5)$ & 0.77 \\
\hline BMI & $27.5(4.2)$ & $26.8(3.3)$ & $27.4(4.4)$ & $26.5(3.3)$ & 0.22 & $27.5(4.5)$ & $26.3(3.2)$ & 0.052 \\
\hline Waist circumference (cm) & $98.4(9.2)$ & $97.8(6)$ & $96.8(9.1)$ & $95.8(6.5)$ & 0.57 & $96.1(9.4)$ & $95.1(6.2)$ & 0.67 \\
\hline Systolic blood pressure (mmHg) & $136.7(17)$ & $140.9(16.4)$ & $126.6(13.9)$ & $130.4(13.3)$ & 0.47 & $129(14.5)$ & $130.4(13.9)$ & 0.6 \\
\hline Diastolic blood pressure (mmHg) & $80.8(11.8)$ & 79 (10.6) & $76.8(9.9)$ & $74.5(9.5)$ & 0.54 & $77.1(11.6)$ & $75.9(8.8)$ & 0.84 \\
\hline $\operatorname{LDL}(\mathrm{mg} / \mathrm{dl})$ & $128.7(38.3)$ & $137.6(35.2)$ & $129(31.3)$ & $135.2(36.9)$ & 0.54 & $130(26.2)$ & $131.7(37.3)$ & 0.19 \\
\hline $\mathrm{TG}(\mathrm{mg} / \mathrm{dl})$ & $188.6(383.9)$ & $146.5(58.5)$ & $150.2(100.4)$ & $140.1(70.3)$ & 0.66 & $152.4(127.5)$ & $161.5(77.9)$ & 0.28 \\
\hline $\mathrm{HDL}(\mathrm{mg} / \mathrm{dl})$ & $64.9(19.9)$ & $58.9(12.7)$ & $63.5(17.3)$ & $60(13.6)$ & 0.2 & $65.6(18.8)$ & $59.4(15.2)$ & 0.94 \\
\hline FBS (mg/dl) & $96.2(11.4)$ & $97.2(24.9)$ & $101.2(17.2)$ & $96.4(16.2)$ & 0.098 & $98.2(21.2)$ & $96.2(16.1)$ & 0.42 \\
\hline $\mathrm{HbA1c}(\%) \mathrm{NGSP}$ & $5.6(0.4)$ & $5.6(0.4)$ & $5.6(0.4)$ & $5.5(0.3)$ & 0.18 & $5.6(0.5)$ & $5.53(0.4)$ & 0.28 \\
\hline $\mathrm{PD} \geq 4 \mathrm{~mm}$ (\% of sites) & $15.1(14.9)$ & $19.1(16.3)$ & $15.8(16.0)$ & $11.3(10.0)$ & $0.000^{*}$ & $16.0(16.5)$ & $10.4(10.2)$ & $0.000^{*}$ \\
\hline BOP (\% of sites) & $20.0(18.4)$ & $25.3(21.4)$ & $19.4(19.2)$ & $14.3(11.5)$ & $0.001^{*}$ & $18.7(18.7)$ & $12.9(12.9)$ & $0.002^{*}$ \\
\hline
\end{tabular}

Data are presented as mean (standard deviation) (for all such values). Statistical analysis using ANCOVA

*Statistically significant $p$ values for between-group differences determined by ANCOVA with sex and baseline values as covariate

Subgroup analysis, shown in Tables 4 and 5, was performed to assess the deviation from treatment types. Prevalence of periodontitis was $100 \%$ among all 82 participants. Among them, 29 (ITG: $C T G=13: 16$ ) participants had missing teeth, and 53 (ITG: $C T G=26: 27$ ) had periodontitis alone. Among the participants with periodontitis alone, body fat mass $(p=0.004)$ was significantly higher, and body fat rate $(p=0.005)$ and body water rate $(p=0.048)$ were significantly lower in ITG than in CTG at $1 \mathrm{M}$. Among participants with missing teeth, systolic blood pressure $(p=0.020)$ was significantly higher at $1 \mathrm{M}$ in ITG than in CTG. At $3 \mathrm{M}$, lean mass $(p=0.005)$, muscle mass $(p=0.005)$, estimated bone mass $(p=0.009)$, and body water mass $(p=0.017)$ were significantly lower in ITG than in CTG.

Results of comparison between dropouts and those who retained through out the study at baseline is shown in Table 6. There were significant differences in height and missing teeth at baseline between participants who retained throughout the study period and those who retired. Height $(p=0.023)$ and missing teeth $(p=0.014)$ were significantly higher among the dropouts, respectively. Periodontal status ( $\mathrm{PPD} \geq 4 \mathrm{~mm}$ and $\mathrm{BOP}$ ) among dropouts tended to be worse than those who retained.

\section{Discussion}

This trial was a novel approach to identify the combined effect of dental intervention, including periodontal treatment and prosthodontics, with lifestyle guidance on MetS. The null hypothesis was rejected because body water rate was significantly higher, and FBS level tended to be lower in ITG than in CTG at 1M. In addition, significantly higher lean mass and muscle mass, significantly lower body weight, and tendency of lower BMI in ITG than in CTG at 3M were observed.

Higher body water rate, observed in ITG, implied increase in body tissue other than fat. The changes in body water, weight, lean mass, and muscle mass indicated reduction of weight without losing the essential components that build the body. Moreover, along with the reduction of weight, increase in the proportion of muscle was observed in the ITG. Difference in body composition between ITG and CTG could be considered as an effect of the dental treatment that had been performed in ITG alone. Thus, enhancement in self-awareness and suppression of inflammatory cascade could be the possible causes. Kobayashi [13] and Ylöstalo [31] discovered that frequency of oral health behaviors, which is considered as the ability of self-awareness, is related to 
Table 3 Comparisons of changes in anthropometric measurements, dental measurements, blood pressure, and blood samples within the control $(n=43)$ and intervention $(n=39)$ groups before and after treatment

\begin{tabular}{|c|c|c|c|c|}
\hline \multirow[t]{2}{*}{ Time point } & \multicolumn{2}{|l|}{ Control } & \multicolumn{2}{|l|}{ Intervention } \\
\hline & Difference in mean value & $p$ value* & Difference in mean value & $p$ value* \\
\hline \multicolumn{5}{|l|}{ Weight (kg) } \\
\hline Baseline-1 months & 0.17 & 1.000 & 0.84 & 0.097 \\
\hline Baseline-3 months & 0.05 & 1.000 & 1.35 & $0.014^{*}$ \\
\hline $1-3$ months & -0.13 & 1.000 & 0.5 & 0.710 \\
\hline \multicolumn{5}{|l|}{ Body fat rate (\%) } \\
\hline Baseline-1 months & 0.49 & 0.680 & 1.02 & $0.007^{*}$ \\
\hline Baseline- 3 months & 0.94 & 0.085 & 0.76 & 0.240 \\
\hline $1-3$ months & 0.45 & 0.798 & -0.26 & 1.000 \\
\hline \multicolumn{5}{|l|}{ Body fat mass $(\mathrm{kg})$} \\
\hline Baseline-1 months & 0.34 & 1.000 & 1.01 & $0.005^{*}$ \\
\hline Baseline-3 months & 0.58 & 0.711 & 0.97 & 0.055 \\
\hline $1-3$ months & 0.24 & 1.000 & -0.04 & 1.000 \\
\hline \multicolumn{5}{|l|}{ Lean mass (kg) } \\
\hline Baseline-1 months & -0.16 & 1.000 & -0.17 & 1.000 \\
\hline Baseline-3 months & -0.53 & 0.098 & 0.37 & 0.770 \\
\hline $1-3$ months & -0.37 & 0.630 & 0.54 & 0.260 \\
\hline \multicolumn{5}{|l|}{ Muscle mass (kg) } \\
\hline Baseline-1 months & -0.14 & 1.000 & -0.15 & 1.000 \\
\hline Baseline-3 months & -0.51 & 0.096 & 0.35 & 0.760 \\
\hline $1-3$ months & -0.37 & 0.560 & 0.50 & 0.260 \\
\hline \multicolumn{5}{|c|}{ Estimated bone mass $(\mathrm{kg})$} \\
\hline Baseline-1 months & -0.02 & 0.830 & -0.02 & 0.680 \\
\hline Baseline-3 months & -0.06 & 0.230 & 0.02 & 1.000 \\
\hline $1-3$ months & -0.01 & 1.000 & 0.04 & 0.300 \\
\hline \multicolumn{5}{|l|}{ Body water mass $(\mathrm{kg})$} \\
\hline Baseline-1 months & 0.00 & 1.000 & -0.54 & 0.150 \\
\hline Baseline-3 months & -0.21 & 1.000 & 0.11 & 1.000 \\
\hline $1-3$ months & -0.22 & 0.750 & 0.654 & $0.009^{*}$ \\
\hline \multicolumn{5}{|l|}{ Body water rate (\%) } \\
\hline Baseline-1 months & -0.24 & 1.000 & -1.24 & $0.000^{*}$ \\
\hline Baseline-3 months & -0.56 & 0.550 & -0.74 & 0.059 \\
\hline $1-3$ months & -3.26 & 0.670 & 0.51 & 0.210 \\
\hline \multicolumn{5}{|l|}{ BMI } \\
\hline Baseline- 1 months & 0.05 & 1.000 & 0.28 & 0.130 \\
\hline Baseline-3 months & 0.01 & 1.000 & 0.48 & $0.016^{*}$ \\
\hline $1-3$ months & -0.04 & 1.000 & 0.20 & 0.650 \\
\hline \multicolumn{5}{|c|}{ Waist circumference $(\mathrm{cm})$} \\
\hline Baseline-1 months & 1.60 & $0.003^{*}$ & 1.92 & $0.004^{*}$ \\
\hline Baseline-3 months & 2.27 & $0.001^{*}$ & 2.67 & $0.000^{*}$ \\
\hline $1-3$ months & 0.67 & 0.250 & 0.75 & 0.390 \\
\hline \multicolumn{5}{|c|}{ Systolic blood pressure (mmHg) } \\
\hline Baseline-1 months & 10.09 & $0.000^{*}$ & 10.51 & $0.000^{*}$ \\
\hline Baseline-3 months & 7.72 & $0.000^{*}$ & 10.49 & $0.001^{*}$ \\
\hline $1-3$ months & -2.37 & 0.750 & -0.018 & 0.750 \\
\hline \multicolumn{5}{|c|}{ Diastolic blood pressure $(\mathrm{mmHg})$} \\
\hline Baseline-1 months & 4.07 & $0.016^{*}$ & 4.54 & $0.004^{*}$ \\
\hline Baseline-3 months & 3.73 & $0.020^{*}$ & 3.12 & 0.073 \\
\hline
\end{tabular}


Table 3 (continued)

\begin{tabular}{|c|c|c|c|c|}
\hline \multirow[t]{2}{*}{ Time point } & \multicolumn{2}{|l|}{ Control } & \multicolumn{2}{|l|}{ Intervention } \\
\hline & Difference in mean value & $p$ value $*$ & Difference in mean value & $p$ value* \\
\hline $1-3$ months & -0.34 & 1.000 & -1.42 & 1.000 \\
\hline \multicolumn{5}{|l|}{ LDL (mg/dl) } \\
\hline Baseline- 1 months & -0.23 & 1.000 & 2.33 & 1.000 \\
\hline Baseline-3 months & -1.21 & 1.000 & 5.85 & 0.410 \\
\hline $1-3$ months & -0.98 & 1.000 & 3.51 & 1.000 \\
\hline \multicolumn{5}{|l|}{$\mathrm{TG}(\mathrm{mg} / \mathrm{dl})$} \\
\hline Baseline-1 months & 38.42 & 1.000 & 6.46 & 1.000 \\
\hline Baseline-3 months & 36.19 & 1.000 & -14.95 & 0.720 \\
\hline $1-3$ months & -2.23 & 1.000 & -21.41 & 0.091 \\
\hline \multicolumn{5}{|l|}{$\mathrm{HDL}(\mathrm{mg} / \mathrm{dl})$} \\
\hline Baseline-1 months & 1.42 & 0.650 & -1.10 & 1.000 \\
\hline Baseline-3 months & -0.67 & 1.000 & -0.46 & 1.000 \\
\hline $1-3$ months & -2.09 & 0.370 & 0.64 & 1.000 \\
\hline \multicolumn{5}{|l|}{$\mathrm{FBS}(\mathrm{mg} / \mathrm{dl})$} \\
\hline Baseline-1 months & -5.05 & 0.170 & 0.85 & 1.000 \\
\hline Baseline-3 months & -2.05 & 1.000 & 1.08 & 1.000 \\
\hline $1-3$ months & 3.00 & 1.000 & 0.23 & 1.000 \\
\hline \multicolumn{5}{|l|}{$\mathrm{HbA1c}(\%) \mathrm{NGSP}$} \\
\hline Baseline-1 months & 0.03 & 0.850 & 0.06 & 0.300 \\
\hline Baseline-3 months & 0.01 & 1.000 & 0.04 & 0.750 \\
\hline $1-3$ months & -0.02 & 1.000 & -0.02 & 1.000 \\
\hline \multicolumn{5}{|l|}{$\mathrm{PD} \geq 4 \mathrm{~mm}$ (\% of sites) } \\
\hline Baseline-1 months & -0.70 & 1.000 & 7.80 & 0.000 \\
\hline Baseline-3 months & -0.90 & 1.000 & 8.70 & 0.000 \\
\hline $1-3$ months & -0.20 & 1.000 & 0.90 & 1.000 \\
\hline \multicolumn{5}{|l|}{ BOP (\% of sites) } \\
\hline Baseline-1 months & 0.60 & 1.000 & 11.00 & 0.000 \\
\hline Baseline-3 months & 1.30 & 1.000 & 12.40 & 0.000 \\
\hline $1-3$ months & 0.70 & 1.000 & 1.40 & 0.949 \\
\hline
\end{tabular}

Data were presented as differences in mean value. A negative value for within-group changes denotes an increase of variable between time points. Statistical analysis using Repeated ANOVA

*Statistically significant $p$ values for within-group changes

lower prevalence of MetS or obesity. Maintaining the oral environment by TBI and periodontal treatment might have motivated participants' self-awareness, which could have encouraged their improvement in diet and exercise. Moreover, Wilcox [32] and Bullon [33] investigated the inflammatory cascade between periodontitis and MetS. IR, strongly related to diabetes, increases with the existence of excessive visceral fat and lack of exercise. Adipocytokine, which is secreted from visceral fat, mediates the release of inflammatory cytokines and reactive oxygen species (ROS) from leucocytes that would further activate host immune reaction, resulting in periodontium destruction. Dandona [34] suggested that consistent periodontitis leads to further production of inflammatory cytokines, which brings about systemic inflammation and increase in IR, leading to progression of diabetes. Furthermore, ROS and Porphyromonas gingivalis have also been causes of vascular dysfunction, leading to hypertension and atherosclerosis [35]. In this study, it is considered that dental treatment could block the cascade by maintaining a good standard of oral hygiene and relieving inflammation, which may lead to possible improvements in MetS and its related factors.

Considering the results of comparisons within groups, waist circumference in both groups declined, implying a reduction in visceral fat in both groups. According to Fang, change in waist circumference is caused by fluctuation of the visceral fat [36]. Comparing current results with this finding, dietary and exercise guidance might have encouraged reduction of caloric intake and increase 
Table 4 Comparisons of anthropometric measurements, dental measurements, blood pressure, and blood samples between the control group $(n=16)$ and the intervention group $(n=13)$ before and after treatment among patients with missing teeth

\begin{tabular}{|c|c|c|c|c|c|c|c|c|}
\hline & \multirow{2}{*}{\multicolumn{2}{|c|}{$\frac{\text { Baseline }}{\text { Mean }}$}} & \multicolumn{3}{|l|}{$1 M$} & \multicolumn{3}{|l|}{$3 M$} \\
\hline & & & \multicolumn{2}{|l|}{ Mean } & \multirow[t]{2}{*}{$p$ value* } & \multicolumn{2}{|l|}{ Mean } & \multirow[t]{2}{*}{$p$ value ${ }^{*}$} \\
\hline & Control & Intervention & Control & Intervention & & Control & Intervention & \\
\hline Weight (kg) & $79.7(18.3)$ & $71.1(9.1)$ & $79.9(19.5)$ & $71.3(8.5)$ & 0.969 & $80.4(20.1)$ & $69.3(8.5)$ & 0.167 \\
\hline Body fat rate (\%) & $35.8(9.6)$ & $27.9(6.7)$ & $35.0(9.1)$ & $27.6(6.1)$ & 0.691 & $34.2(10.5)$ & $27.8(5.8)$ & 0.566 \\
\hline Body fat mass (kg) & $29.1(11.9)$ & $19.9(5.4)$ & $28.7(12.3)$ & $19.7(4.7)$ & 0.710 & $28.4(13.3)$ & $19.3(4.7)$ & 0.984 \\
\hline Lean mass (kg) & $50.6(11.8)$ & $51.2(8.1)$ & $51.2(11.5)$ & $51.6(7.6)$ & 0.928 & $52.0(12.1)$ & $50.0(7.1)$ & $0.005^{*}$ \\
\hline Muscle mass (kg) & $47.8(11.3)$ & $48.5(7.8)$ & $48.3(11.0)$ & $48.8(7.3)$ & 0.918 & $49.1(11.6)$ & $47.3(6.9)$ & $0.005^{*}$ \\
\hline Estimated bone mass (kg) & $2.8(0.5)$ & $2.8(0.4)$ & $2.9(0.5)$ & $2.8(0.4)$ & 0.962 & $2.9(0.5)$ & $2.7(0.3)$ & $0.009^{*}$ \\
\hline Body water mass (kg) & $36.7(7.7)$ & $35.3(5.1)$ & $36.8(7.2)$ & $36.2(4.6)$ & 0.789 & $37.1(6.6)$ & $34.9(4.6)$ & $0.017^{*}$ \\
\hline Body water rate (\%) & $46.5(5.4)$ & $49.8(3.9)$ & $46.8(5.4)$ & $50.8(2.7)$ & 0.168 & $47.2(6.3)$ & $50.4(4.1)$ & 0.799 \\
\hline BMI & $29.1(5.0)$ & $26.4(2.8)$ & $29.2(5.5)$ & $26.6(2.8)$ & 0.944 & $29.3(5.5)$ & $25.8(2.6)$ & 0.111 \\
\hline Waist circumference (cm) & $103.3(11.1)$ & $97.2(4.9)$ & $102.3(10.5)$ & $95.3(7.0)$ & 0.380 & $101.8(10.7)$ & $93.6(5.2)$ & 0.094 \\
\hline Systolic blood pressure (mmHg) & $136.5(18.5)$ & $140.5(15.4)$ & $122.4(10.7)$ & $133.1(14.5)$ & $0.020^{*}$ & $130.4(12.4)$ & $126.0(10.5)$ & 0.061 \\
\hline Diastolic blood pressure (mmHg) & $77.6(10.7)$ & $77.6(7.1)$ & $73.3(8.5)$ & $73.0(8.8)$ & 0.926 & $76.9(12.3)$ & $72.8(6.5)$ & 0.137 \\
\hline LDL (mg/dl) & $129.7(23.9)$ & $132.2(37.1)$ & $126.7(26.9)$ & $126.5(42.0)$ & 0.449 & $133.2(26.0)$ & $134.4(44.2)$ & 0.657 \\
\hline $\mathrm{TG}(\mathrm{mg} / \mathrm{dl})$ & $155.5(113.4)$ & $132.6(42.3)$ & $157.3(80.8)$ & $135.0(58.3)$ & 0.498 & $152.0(111.6)$ & $153.8(61.0)$ & 0.691 \\
\hline $\mathrm{HDL}(\mathrm{mg} / \mathrm{dl})$ & $60.1(13.8)$ & $57.2(10.3)$ & $58.2(12.7)$ & $57.2(10.2)$ & 0.603 & $62.1(14.3)$ & $55.1(11.9)$ & 0.238 \\
\hline FBS (mg/dl) & $99.7(11.8)$ & $105.2(36.5)$ & $105.6(21.3)$ & $99.5(20.7)$ & 0.171 & $105.4(28.3)$ & $98.8(14.8)$ & 0.170 \\
\hline $\mathrm{HbA1c}(\%)$ NGSP & $5.8(0.5)$ & $5.7(0.4)$ & $5.7(0.5)$ & $5.7(0.4)$ & 0.444 & $5.8(0.5)$ & $5.6(0.4)$ & 0.454 \\
\hline $\mathrm{PD} \geq 4 \mathrm{~mm}$ (\% of sites) & $17.6(15.6)$ & $23.7(17.7)$ & $17.2(16.5)$ & $12.9(9.9)$ & $0.006^{*}$ & $17.1(15.5)$ & $11.8(10.3)$ & $0.004^{*}$ \\
\hline BOP (\% of sites) & $25.1(22.3)$ & $31.3(20.3)$ & $21.4(20.4)$ & $18.0(13.0)$ & 0.130 & $20.5(19.2)$ & $15.8(13.4)$ & 0.129 \\
\hline
\end{tabular}

Data are presented as mean (standard deviation) (for all such values). Statistical analysis using ANCOVA

*Statistically significant $p$ values for between-group differences determined by ANCOVA with sex and baseline values as covariate

of metabolism due to exercise, which may have led to reduction of visceral fat. Moreover, FBS tendency to be lower at $1 \mathrm{M}$ in ITG than in CTG could be attributed to this cascade. However, the decrement of blood pressure and waist circumference in both groups seemed to be obtained from dietary and exercise guidance rather than dental treatment.

Body water mass LDL, HDL, and HbA1c changes had no marked significance or tendency in the overall result. Change of body water may not have been detected by mass because the variation of total weight between individuals was sizeable. Regarding LDL results, our result seemed to be consistent with that in a previous report by Tuomilehto [37] and Munakata [29], in which it was found that LDL level had not changed after significant reduction of weight among obese participants. Moreover, Siri-Tarino and Krauss explained that food intake would not be directly reflected on blood test data because the lipoprotein particles need to be produced in the liver before they are distributed into peripheral blood as HDL and LDL [38]. If long-term outcome measurement could be performed, the result might have become more obvious. However, the intake of saturated fatty acid should be assessed later on to investigate the dietary effect. According to Little, HbA1c has been used as an indication of average glucose level because it reflects blood glucose of the past 8-12 weeks [39]. In addition, the intra-individual variation in the non-diabetic population is very small. Considering the study period and diabetic statuses of the participants in this study, the result seems to be reasonable.

Subgroup analysis was performed to assess the deviation from treatment types. Comparing subgroup results with the overall results of the study, significant deviation has not been observed in subgroups. Both subgroups showed similar trends with the overall result, although the missing teeth group appeared to lack in sample size. At baseline, height and weight were significantly higher in ITG than in CTG among patients with periodontitis alone. However, body fat rate and body fat mass were lower in ITG than in CTG among patients with missing teeth at baseline. Considering these deviations in baseline data, there seems to be no significant deviation between subgroups.

Munakata performed an RCT, intending to reduce the weights of patients with MetS by lifestyle guidance [29]. 
Table 5 Comparisons of anthropometric measurements, dental measurements, blood pressure, and blood samples between the control group $(n=27)$ and the intervention group $(n=26)$ before and after treatment among patients with periodontitis alone

\begin{tabular}{|c|c|c|c|c|c|c|c|c|}
\hline & \multirow{2}{*}{\multicolumn{2}{|c|}{$\frac{\text { Baseline }}{\text { Mean }}$}} & \multicolumn{3}{|l|}{$1 \mathrm{M}$} & \multicolumn{3}{|l|}{$3 M$} \\
\hline & & & \multicolumn{2}{|l|}{ Mean } & \multirow[t]{2}{*}{$p$ value* } & \multicolumn{2}{|l|}{ Mean } & \multirow[t]{2}{*}{$p$ value* } \\
\hline & Control & Intervention & Control & Intervention & & Control & Intervention & \\
\hline Weight (kg) & $70.6(10.0)$ & 76.9 .50 & $70.2(10.1)$ & $74.6(9.4)$ & 0.089 & $70.1(10.0)$ & $74.8(9.1)$ & 0.495 \\
\hline Body fat rate (\%) & $30.0(10.3)$ & $30.6(8.7)$ & $29.8(10.0)$ & $29.2(8.8)$ & $0.005^{*}$ & $29.5(10.1)$ & $29.5(8.8)$ & 0.280 \\
\hline Body fat mass (kg) & $21.4(8.5)$ & $23.3(7.6)$ & $21.1(8.4)$ & $21.8(7.4)$ & $0.004^{*}$ & $20.9(8.5)$ & $22.1(7.3)$ & 0.259 \\
\hline Lean mass (kg) & $49.2(9.1)$ & $52.7(9.4)$ & $49.1(8.7)$ & $52.8(9.4)$ & 0.444 & $49.2(8.8)$ & $52.8(9.4)$ & 0.679 \\
\hline Muscle mass (kg) & $46.5(8.7)$ & $49.9(9.0)$ & $46.4(8.4)$ & $49.9(9.1)$ & 0.461 & $46.5(8.5)$ & $49.9(9.1)$ & 0.723 \\
\hline Estimated bone mass (kg) & $2.7(0.4)$ & $2.8(0.4)$ & $2.7(0.4)$ & $2.9(0.4)$ & 0.263 & $2.7(0.4)$ & $2.9(0.4)$ & 0.225 \\
\hline Body water mass (kg) & $35.2(5.7)$ & $36.5(5.6)$ & $35.1(5.1)$ & $36.9(6.1)$ & 0.210 & $35.3(5.3)$ & $36.6(5.9)$ & 0.931 \\
\hline Body water rate (\%) & $50.1(5.7)$ & $48.1(4.3)$ & $50.3(5.0)$ & $49.5(4.9)$ & $0.048^{*}$ & $50.6(5.4)$ & $48.9(4.7)$ & 0.905 \\
\hline BMI & $26.5(3.3)$ & $26.9(3.6)$ & $26.4(3.4)$ & $26.4(3.6)$ & 0.056 & $26.3(3.3)$ & $26.5(3.5)$ & 0.371 \\
\hline Waist circumference (cm) & $95.4(6.4)$ & $98.0(6.6)$ & $93.5(6.3)$ & $96.1(6.4)$ & 0.698 & $92.7(6.6)$ & $95.8(606)$ & 0.292 \\
\hline Systolic blood pressure (mmHg) & $136.8(16.5)$ & $141.0(17.2)$ & $129.1(15.1)$ & $129.0(12.7)$ & 0.497 & $128.1(15.7)$ & $132.6(15.1)$ & 0.617 \\
\hline Diastolic blood pressure (mmHg) & $82.7(12.2)$ & $79.7(12.1)$ & $78.8(10.3)$ & $75.1(10.0)$ & 0.408 & $77.2(11.4)$ & $77.4(9.6)$ & 0.450 \\
\hline $\mathrm{LDL}(\mathrm{mg} / \mathrm{dl})$ & $128.2(31.1)$ & $140.2(34.6)$ & $130.3(34.0)$ & $139.6(34.2)$ & 0.813 & $128.0(26.6)$ & $130.4(34.2)$ & 0.202 \\
\hline $\mathrm{TG}(\mathrm{mg} / \mathrm{dl})$ & $208.2(479.2)$ & $153.5(64.7)$ & $145.9(111.6)$ & $142.6(76.5)$ & 0.928 & $152.6(138.2)$ & $165.3(85.9)$ & 0.183 \\
\hline $\mathrm{HDL}(\mathrm{mg} / \mathrm{dl})$ & $67.8(21.1)$ & $59.8(13.9)$ & $66.7(19.0)$ & $61.4(15.0)$ & 0.308 & $67.7(21.0)$ & $61.5(16.5)$ & 0.517 \\
\hline FBS (mg/dl) & $94.1(10.8)$ & $93.3(15.8)$ & $98.6(14.1)$ & $94.8(13.6)$ & 0.323 & $94.0(14.7)$ & $94.8(16.8)$ & 0.758 \\
\hline $\mathrm{HbA1c}(\%) \mathrm{NGSP}$ & $5.6(0.3)$ & $5.5(0.4)$ & $5.6(0.4)$ & $5.5(0.3)$ & 0.068 & $5.5(0.4)$ & $5.5(0.3)$ & 0.520 \\
\hline $\mathrm{PD} \geq 4 \mathrm{~mm}$ (\% of sites) & $13.6(14.5)$ & $16.8(15.4)$ & $14.9(15.9)$ & $10.5(10.1)$ & $0.001^{*}$ & $15.4(17.3)$ & $9.7(10.3)$ & $0.000^{*}$ \\
\hline BOP (\% of sites) & $17.1(15.3)$ & $22.3(21.7)$ & $18.2(18.7)$ & $12.5(10.4)$ & $0.006^{*}$ & $17.7(18.7)$ & $11.4(12.7)$ & $0.006^{*}$ \\
\hline
\end{tabular}

Data are presented as mean (standard deviation) (for all such values). Statistical analysis using ANCOVA

*Statistically significant $p$ values for between-group differences determined by ANCOVA with sex and baseline values as covariate

Patients with MetS were provided initial lifestyle guidance. Thereafter, the experimental group received multiple individualized lectures every 2 months, while the control group was requested to reduce weight on their own. Improvements on waist circumference and FBS level in the experimental group compared with the control group were revealed. Waist circumference and FBS level in our study did not show significant improvement in comparison between groups. Compared with our intervention, their lifestyle guidance had been remarkably intense, and this intensity may have taken effect. Baeza had compared nine RCTs that examined the effect of dental treatment on patients with diabetes, and they revealed SRP to be effective in reducing HbA1c levels [14]. Periodontal intervention included TBI and SRP with the primary outcome on HbA1c and CRP levels. Saengtipbovorn and Taneepanichskul had provided lifestyle guidance followed by oral hygiene instructions to the experimental group and medical consultation to the control group among patients with diabetes in their RCT [18]. As a result, HbA1c and FBS levels, and periodontal status improved 6 months after intervention. Compared with these two trials, our participants were mainly those who had abdominal obesity; therefore, the intraindividual variation in $\mathrm{HbA1c}$ level was considered very small. Having a tendency of lower FBS level in ITG than in CTG, periodontal treatment had possibly improved diabetic statuses of our participants in ITG. Papageorgiou compared 15 RCTs that had examined the effect of periodontal treatment on obese participants [16]. TNF $\alpha$ and $\mathrm{HbA} 1 \mathrm{c}$ levels after periodontal therapy were significantly higher in overweight/obese patients than in normal weight patients. Lopez reported that reduction of periodontal inflammation either with SRP and systemic antibiotics with TBI significantly reduced CRP levels at 9 months in patients with MetS, after intervention [17]. The difference between our trial and these two trials was the existence of lifestyle guidance. Anthropometric improvement in the intervention group of our study may be due to the combination of dental intervention and lifestyle guidance. Improvement in glycemic condition seemed to be the common point with Lopez' study.

\section{Limitation}

Below are the possible limitations of this study. First, we guided the participants on diet and exercise. Participants 
Table 6 Baseline characteristics of the Dropout group and the difference with the Retained group

\begin{tabular}{|c|c|c|c|c|c|}
\hline & \multicolumn{3}{|c|}{ Dropout group (D) } & \multirow{3}{*}{$\begin{array}{l}\text { Retained group (R) } \\
\text { Total }(\mathrm{n}=82)\end{array}$} & \multirow{3}{*}{$\begin{array}{l}\text { Difference } \\
\text { between D-R } \\
p \text { value }\end{array}$} \\
\hline & \multicolumn{2}{|l|}{ Group } & \multirow[t]{2}{*}{ Total $(n=30)$} & & \\
\hline & Control $(n=13)$ & Intervention $(n=17)$ & & & \\
\hline Age (years), mean (SD) & $55.8(11.8)$ & & $54.7(10.3)$ & $57.5(9.9)$ & $0.201^{\mathrm{a}}$ \\
\hline Gender, n (\%) & & & & & $0.269^{b}$ \\
\hline Male & $11(84.6 \%)$ & $10(58.8 \%)$ & $21(70 \%)$ & $48(58.5 \%)$ & \\
\hline Female & $2(15.4 \%)$ & $7(41.2 \%)$ & $9(30 \%)$ & $34(41.5 \%)$ & \\
\hline Body height (cm), mean (SD) & $170.9(7.7)$ & $168(7.2)$ & $169.2(7.4)$ & $165.2(8.4)$ & $0.023^{\mathrm{a} *}$ \\
\hline Body weight (kg), mean (SD) & $77.4(10.2)$ & $76.9(14.5)$ & $77.1(12.6)$ & $74.1(12.1)$ & $0.260^{\mathrm{a}}$ \\
\hline BMI, mean (SD) & $26.6(3.4)$ & $27.1(4.0)$ & $26.9(3.7)$ & $27.1(3.8)$ & $0.743^{\mathrm{a}}$ \\
\hline Waist circumference (cm), mean (SD) & $91.7(8.0)$ & $98.9(8.9)$ & $98.4(8.4)$ & $98.1(7.8)$ & $0.851^{\mathrm{a}}$ \\
\hline Types of treatment in need, $\mathrm{n}(\%)$ & & & & & \\
\hline Periodontal treatment & $13(100 \%)$ & $17(100 \%)$ & $30(100 \%)$ & $82(100 \%)$ & \\
\hline Fabrication of fixed partial denture & $1(7.7 \%)$ & $1(5.9 \%)$ & $2(6.7 \%)$ & $3(3.7 \%)$ & \\
\hline Fabrication of removable partial denture & $4(30.8 \%)$ & $9(52.9 \%)$ & $13(43.3 \%)$ & $26(31.7 \%)$ & \\
\hline $\mathrm{PD} \geq 4$ mm (\% of sites), mean (SD) & $28.8(23.1)$ & $19.5(16.4)$ & $23.6(19.8)$ & $17.0(15.6)$ & $0.070^{\mathrm{a}}$ \\
\hline BOP (\% of sites), mean (SD) & $30.6(20.9)$ & $29.6(23.7)$ & $30.0(22.1)$ & $22.6(19.9)$ & $0.092^{\mathrm{a}}$ \\
\hline Missing tooth (n), mean (SD) & $4.9(3.9)$ & $6.2(5.3)$ & $5.7(4.7)$ & $3.4(4.1)$ & $0.014^{\mathrm{a} *}$ \\
\hline
\end{tabular}

Data are presented as mean (standard deviation) (for all such values)

a Statistical analysis using student's t-test

b Statistical analysis using chi-square test

*Statistically significant $p$ values for between-group differences

were required to respond to the brief diet-history questionnaire (BDHQ); however, this would not be assessed in this paper. However, assessment for exercise intensity was not performed in the first place. Second, the final assessment of the outcomes was at post 3 months in this study because 3 months appeared to be the ethical limit to keep patients from needed dental treatment. If we could come out with a good solution for this point, longterm observation would be desirable. Third, this trial was voluntary; the participants were motivated to get healthier and to undergo dental treatment for dental health. Therefore, it seems to be doubtful whether the outcomes were simply from the intervention or from their motivations. Fourth, setting waist circumference as a primary outcome could be considered as one of the limitations. To assess the visceral fat mass more accurately, computed tomography (CT) or magnetic resonance imaging (MRI) scans would be the most appropriate procedures [36]. Although CT has a risk of radiation exposure, requiring $\mathrm{CT}$ and MRI scans for all participants in each assessment (BL, $1 \mathrm{M}$, and $3 \mathrm{M}$ ) would also incur considerable cost and time. According to Fang, visceral fat mass on CT has been correlated with waist circumference [36]. From the report of Matsuzawa, waist circumferences of $85 \mathrm{~cm}$ (men) and $90 \mathrm{~cm}$ (women) are equivalent to $100 \mathrm{~cm}^{2}$ of visceral fat area, and waist circumference is more closely related to visceral fat than BMI [26]. Considering the results of these studies and the feasibility of the procedure, we determined to use waist circumference as the primary outcome to assess the effect of the intervention. Fifth, at baseline, height and missing teeth were significantly higher, and periodontal status $(\mathrm{PPD} \geq 4 \mathrm{~mm}$ and $\mathrm{BOP}$ ) tended to be worse among the dropouts than those who retained. We have done student's t-test to examine if there is any significant difference between controls and treatment group of the dropouts, in which we found that there was no significant difference between each group. It remains unclear, whether the dropouts had any bias effect towards the result of this study, but regarding the result from between-group (Treatment-Control) difference in dropouts, we consider that losing those participants had little effect.

For the future perspective, changes in participants' dietary patterns would be clarified by analyzing the results of BDHQs, which may deepen our understanding regarding the results obtained in this study. If another project were to be launched, a study design that enables longterm observation would be desired to assess the longevity of the treatment effect and the rebound effect. Evaluation of exercise intensity, which was not applied in this project, would also enable multilateral analysis on the effect of lifestyle guidance. 


\section{Conclusion}

As a conclusion, the combination of dental intervention and lifestyle guidance improved both anthropometric and periodontal statuses of patients with MetS.

\section{Acknowledgements}

The authors would like to thank Drs. Pariko Yorozu, Yoshiaki Hanzawa and Yasunori Sakamaki for helpful discussions. This work is supported by Grants-inAid for Scientific Research (KAKENHI) — Scientific Research B 16H05521

\section{Authors' contributions}

MD performed randomization, dietary and exercise guidance, outcome assessment, and statistical analysis and was a major contributor in writing the manuscript. YK, KO, YM and SM directed this project. YK, MK, MI and HS performed dental interventions including prosthodontics and periodontal treatment. TM directed dietary and exercise guidance of this project. All authors read and approved the final manuscript.

\section{Funding}

This study was funded by Grants-in-Aid for Scientific Research (KAKENHI) - Scientific Research B 16H05521.

\section{Availability of data and materials}

The datasets used and/or analyzed during the current study available from the corresponding author on reasonable request.

\section{Ethics approval and consent to participate}

The trial protocol was approved by the Ethics Committee of the Faculty of Dentistry, Tokyo Medical and Dental University (TMDU; Registration No. D2016-028, date of final registration 25/1/2019), and is registered in the University Hospital Medical Information Network Center (UMIN-CTR Clinical Trial, Unique Trial No. UMIN000022753). The trial was carried out at TMDU Dental Hospital from December 2016 to September 2019. All procedures performed in this study that involved human participants were in accordance with the ethical standards of the Ethics Committee of the Faculty of Dentistry, TMDU and with the 1964 Helsinki declaration and its later amendments or comparable ethical standards. All participants provided written informed consent before participation in the study.

\section{Consent for publication}

Written informed consent was obtained from all participants for publication of this report.

\section{Competing interests}

The authors declare that there is no competing interest.

\begin{abstract}
Author details
${ }^{1}$ Gerodontology and Oral Rehabilitation, Graduate School of Medical and Dental Sciences, Tokyo Medical and Dental University, Yushima, Bunkyo-ku, Tokyo, Japan. ${ }^{2}$ General Dentistry, Graduate School of Medica and Dental Sciences, Tokyo Medical and Dental University, Tokyo, Japan. ${ }^{3}$ Department of Respiratory Medicine, Graduate School of Medical and Dental Sciences, Tokyo Medical and Dental University, Tokyo, Japan. ${ }^{4}$ Department of Health Science and Physical Education, College of Liberal Arts and Sciences, Tokyo Medical and Dental University, Tokyo, Japan. ${ }^{5}$ Yokohama City Minato Red Cross Hospital Medical Center for Allergic and Immune Diseases, Yokohama, Japan.
\end{abstract}

Received: 23 September 2020 Accepted: 14 December 2020 Published online: 06 January 2021

\section{References}

1. Cardiovascular diseases (CVDs) WHO. Obesity and Overweight. WHO. N.p., n.d. Web. 28 Nov 2012. http://www.who.int/mediacentre/facts heets/fs311/en/. https://www.who.int/news-room/fact-sheets/detail/ cardiovascular-diseases-(cvds).
2. Japan Ministry of Health, Labour and Welfare 2006 メタボリックシンド ローム該当者・予備軍の状況. https://www.mhlw.go.jp/bunya/kenkou/ seikatsu/06.html.

3. Matsuzawa Y. Metabolic syndrome-definition and diagnostic criteria in Japan. J Atheroscler Thromb. 2005;12:301. https://doi.org/10.5551/ jat.12.301.

4. Examination Committee of Criteria for "obesity disease" in Japan; Japan Society for the Study of Obesity. New criteria for "obesity disease" in Japan. Circ J. 2002;66:987-92. https://doi.org/10.1253/circj.66.987.

5. Expert Panel on Detection, Evaluation, and Treatment of High Blood Cholesterol in Adults. Executive summary of the third report of the National Cholesterol Education Program (NCEP) expert panel on detection, evaluation, and treatment of high blood cholesterol in adults (Adult Treatment Panel III). JAMA. 2001;285:2486-97. https://doi.org/10.1001/ jama.285.19.2486

6. Saito T, Shimazaki Y, Sakamoto M. Obesity and periodontitis. N Engl J Med. 1998:339:482-3. https://doi.org/10.1056/NEJM199808133390717.

7. Al-Zahrani MS, Bissada NF, Borawskit EA. Obesity and periodontal disease in young, middle-aged, and older adults. J Periodontol. 2003;74:610-5. https://doi.org/10.1902/jop.2003.74.5.610.

8. Lamster IB, Pagan M. Periodontal disease and the metabolic syndrome. Int Dent J. 2017;67:67-77. https://doi.org/10.1111/idj.12264.

9. Sanz M, Ceriello A, Buysschaert M, Chapple I, Demmer RT, Graziani F, Herrera D, Jepsen S, Lione L, Madianos P, Mathur M, Montanya E, Shapira $L$, Tonetti M, Vegh D. Scientific evidence on the links between periodontal diseases and diabetes: consensus report and guidelines of the joint workshop on periodontal diseases and diabetes by the International Diabetes Federation and the European Federation of Periodontology. J Clin Periodontol. 2018:45:138-49. https://doi.org/10.1111/jcpe.12808.

10. Ormazabal V, Nair S, Elfeky O, Aguayo C, Salomon C, Zuñiga FA. Association between insulin resistance and the development of cardiovascular disease. Cardiovasc Diabetol. 2018;17(1):122. https://doi.org/10.1186/ s12933-018-0762-4.PMID:30170598;PMCID:PMC6119242.

11. Hirano T. Pathophysiology of diabetic dyslipidemia. J Atheroscler Thromb. 2018;25(9):771-82. https://doi.org/10.5551/jat.RV17023.

12. Lalla E, Papapanou PN. Diabetes mellitus and periodontitis: a tale of two common interrelated diseases. Nat Rev Endocrinol. 2011;7(12):738-48. https://doi.org/10.1038/nrendo.2011.106 PMID: 21709707.

13. Kobayashi Y, Niu K, Guan L, Momma H, Guo H, Cui Y, Nagatomi R. Oral health behavior and metabolic syndrome and its components in adults. J Dent Res. 2012;91:479-84. https://doi.org/10.1177/0022034512440707.

14. Baeza M, Morales A, Cisterna C, Cavalla F, Jara G, Isamitt Y, Pino P, Gamonal J. Effect of periodontal treatment in patients with periodontitis and diabetes: systematic review and meta-analysis. J Appl Oral Sci. 2020;28:e20190248. https://doi.org/10.1590/1678-7757-2019-0248.

15. Hayashi J, Hasegawa A, Hayashi K, Suzuki T, Ishii M, Otsuka H, Yatabe K, Goto S, Tatsumi J, Shin K. Effects of periodontal treatment on the medical status of patients with type 2 diabetes mellitus: a pilot study. BMC Oral Health. 2017;17:77. https://doi.org/10.1186/s12903-017-0369-2.

16. Papageorgiou SN, Reichert C, Jäger A, Deschner J. Effect of overweight/ obesity on response to periodontal treatment: systematic review and a meta-analysis. J Clin Periodontol. 2015;42:247-61. https://doi. org/10.1111/jcpe.12365.

17. López NJ, Quintero A, Casanova PA, Ibieta Cl, Baelum V, López R. Effects of periodontal therapy on systemic markers of inflammation in patients with metabolic syndrome: a controlled clinical trial. J Periodontol. 2012;83:267-78. https://doi.org/10.1902/jop.2011.110227.

18. Saengtipbovorn S, Taneepanichskul S. Effectiveness of lifestyle change plus dental care program in improving glycemic and periodontal status in aging patients with diabetes: a cluster, randomized, controlled trial. J Periodontol. 2015;86:507-15. https://doi.org/10.1902/jop.2015.140563.

19. Miller NA, Roland E, Benhamgar L. Evaluation de l'indice des besoins de la collectivité en matière de traitement des parodontopathies (CPITN) [Evaluation of the CommunityPeriodontal Index of Treatment Needs (CPITN)]. World Health Stat Q. 1994;47(2):65-74.

20. Eichner K. Erneute Uberprüfung der Gruppeneinteilung von Lückengebissen nach Eichner und Anwendungshinweise für morbiditätsstatistische Untersuchungen [Renewed examination of the group classification of partially edentulous arches by Eichner and application advices for studies on morbidity statistics]. Stomatol DDR. 1990;40(8):321-5. 
21. Mizuno T, Tai K. Development and examination of the Total Fitness analysis system TFAS for fitness education for university students. J Health Phys Educ Recreat Dance Univ. 2013;10:31-40. https://doi.org/10.20723/jhprd .10.1.0_31.

22. Tabata I (2006) Exercise Guide 2006 — to prevent lifestyle related disease by increasing physical activity and exercise, and improving fitness. https ://www.jstage.jst.go.jp/article/jhep/37/5/37_511/_pdf.

23. Tabata I (2006) Health Promotion 2006: Exercise and Physical Activity Guide for Health promotion. https://www.nibiohn.go.jp/files/exerc ise_guide.pdf.

24. Japan Ministry of Agriculture Forestry and Fisheries, Food Safety and Consumer Affairs Bureau, Food-based dietary guidelines-Japan, Japanese Food Guide Spinning Top. https://www.mhlw.go.jp/bunya/kenkou/pdf/ eiyou-syokuji5.pdf. http://www.fao.org/nutrition/education/food-dieta ry-guidelines/regions/countries/.

25. Japan Ministry of Health, Labour and Welfare, Annual Health 2009, Labour and Welfare Report 2008-2009 National Specific Health Checkups and Specific Health Guidance. https://www.mhlw.go.jp/english/wp/wp-hw3/ dl/2-007.pdf.

26. Matsuzawa Y, Funahashi T, Nakamura T. The concept of metabolic syndrome: contribution of visceral fat accumulation and its molecular mechanism. J Atheroscler Thromb. 2011;18:629-39. https://doi. org/10.5551/jat.7922.

27. OMRON Digital Automatic Sphygmomanometer HEM-1000. https:// www.healthcare.omron.co.jp/product/hem/hem-1000.html.

28. TANITA MC-780A portable type. https://www.tanita.co.jp/product/g/_ MC78002001/.

29. Munakata M, Honma H, Akasi M, Araki T, Kawamura T, Kubota M, Yokokawa T, Numata Y, Toyonaga T. Repeated counselling improves the antidiabetic effects of limited individualized lifestyle guidance in metabolic syndrome: J-STOP-METS final results. Hypertens Res. 2011;34:612-6. https://doi.org/10.1038/hr.2010.272.

30. SPSS version 17 (IBM Japan). https://www.ibm.com/support/pages/ downloading-ibm-spss-modeler-170?mhsrc $=i b m s e a r c h \_a \& m h q=$ versi on\%2017.
31. Ylöstalo PV, Ek E, Laitinen J, Knuuttila ML. Optimism and life satisfaction as determinants for dental and general health behavior-oral health habits linked to cardiovascular risk factors. J Dent Res. 2003;82:194-9. https:// doi.org/10.1177/154405910308200309.

32. Wilcox G. Insulin and insulin resistance. Clin Biochem Rev. 2005;26:19-39.

33. Bullon P, Morillo JM, Ramirez-Tortosa MC, Quiles JL, Newman HN, Battino M. Metabolic syndrome and periodontitis: is oxidative stress a common link? J Dent Res. 2009;88:503-18. https://doi.org/10.1177/0022034509 337479.

34. Dandona P, Aljada A, Bandyopadhyay A. Inflammation: the link between insulin resistance, obesity and diabetes. Trends Immunol. 2004;25:4-7. https://doi.org/10.1016/j.it.2003.10.013.

35. Touyz RM. Reactive oxygen species. vascular oxidative stress and redox signaling in hypertension what is the clinical significance? Hypertension. 2004;44:248-52. https://doi.org/10.1161/01.HYP.0000138070.47616.9d.

36. Fang $H$, Berg $E$, Cheng $X$, Shen $W$. How to best assess abdominal obesity. Curr Opin Clin Nutr Metab Care. 2018;21:360-5. https://doi.org/10.1097/ MCO.0000000000000485.

37. Tuomilehto J, Lindström J, Eriksson JG, Valle TT, Hämäläinen H, llanneParikka P, Keinänen-Kiukaanniemi S, Laakso M, Louheranta A, Rastas M, Salminen V, Uusitupa M, FinnishDiabetes Prevention Study Group. Prevention of type 2 diabetes mellitus by changes in lifestyle among subjects with impaired glucose tolerance. N Engl J Med. 2001;344:1343-50. https://doi.org/10.1056/NEJM200105033441801.

38. Siri-Tarino PW, Krauss RM. Diet, lipids, and cardiovascular disease. Curr Opin Lipidol. 2016;27:323-8. https://doi.org/10.1097/MOL.0000000000 000310.

39. Little RR, Sacks DB. HbA1c: how do we measure it and what does it mean? Curr Opin Endocrinol Diabetes Obes. 2009;16:113-8. https://doi. org/10.1097/MED.0b013e328327728d.

\section{Publisher's Note}

Springer Nature remains neutral with regard to jurisdictional claims in published maps and institutional affiliations.
Ready to submit your research? Choose BMC and benefit from:

- fast, convenient online submission

- thorough peer review by experienced researchers in your field

- rapid publication on acceptance

- support for research data, including large and complex data types

- gold Open Access which fosters wider collaboration and increased citations

- maximum visibility for your research: over $100 \mathrm{M}$ website views per year

At BMC, research is always in progress.

Learn more biomedcentral.com/submissions 